\title{
Genetic individuality and interspecies altruism: modelling symbiogenesis using different types of symbiotic bacteria
}

\author{
Nikolay Provorov \\ All-Russia Research Institute for Agricultural Microbiology, Shosse Podbel'skogo, 3, Saint \\ Petersburg, 190608, Russian Federation \\ Address correspondence and requests for materials to Nikolay Provorov, \\ provorovnik@yandex.ru
}

\begin{abstract}
In this minireview, we address the trade-off between biological altruism (group adaptation resulting from the ability of an organism to improve the fitness of an associate at the expense of its own fitness) and symbiogenesis - the evolutionary pathway based on genetic integration of non-related species. We address symbiogenesis as a multi-stage process, which involves formation of superspecific hereditary systems - functionally integral symbiogenomes (under the facultative partners' interactions) reorganized into the structurally integral hologenomes (in the obligatory symbioses). The best studied case of symbiogenesis is represented by the evolution of the eukaryotic cell based on transformation of symbiotic bacteria into cellular organelles. This evolution is associated with the deep reduction of microsymbionts' genomes and with allocation of their genes into the hosts. As a result, microsymbionts lost their Genetic INdividuality (GIN), characterized by an ability to implement DNA- and RNA-based template syntheses required for genome maintenance and expression. Under facultative symbiotic dependence on hosts, the partial loss of GIN is due to a "symbiont $\rightarrow$ host" altruism which in the $\mathrm{N}_{2}$-fixing microbe-plant symbioses results in formation of non-reproducible bacterial forms (e.g., intracellular bacteroids in rhizobia or multiple heterocysts in Nostoc). If micro-symbionts lose their ability of autonomous existence (e.g., in the vertically transmitted intracellular symbionts), they are switched to the "forced altruism" in which the GIN reduction is required for the stable persistence of symbionts in hosts. Therefore, organellogenesis involves the sequential increase of the symbionts' dependency on hosts: conditional $\rightarrow$ facultative $\rightarrow$ obligatory $\rightarrow$ absolute. It is associated with the reorganization of microbes into semi-autonomous cellular components, which may be completely devoid of their own genomes.
\end{abstract}

Keywords: facultative and obligatory symbioses, symbiogenesis and organellogenesis, biological altruism, microbe-plant interactions, nodule bacteria (rhizobia), superspecific genetic systems (hologenomes, symbiogenomes), genetic individuality, horizontal and endosymbiotic gene transfer

\section{Introduction}

The theory of symbiogenesis, suggesting the emergence of eukaryotic cells via integration of diverse prokaryotic organisms, is among the milestones in evolutionary biology of the $20^{\text {th }}-21^{\text {st }}$ centuries (Mereschkowsky, 1910; Kozo-Polyansky, 1924; Margulis, 1993; Smith and Keeling, 2015). It assumes a number of evolutionary patterns and mechanisms that go far beyond the natural selection theory, according to which novel species arise through accumulation of random genetic changes that emerged in ancestral species. The evolutionary processes considered by this theory assume the increased fitness of free-living organisms, while cooperative interactions are regarded as "side effects" of individual adaptations (Maynard Smith, 1989). By contrast, the symbiogenesis theory considers that ma- 


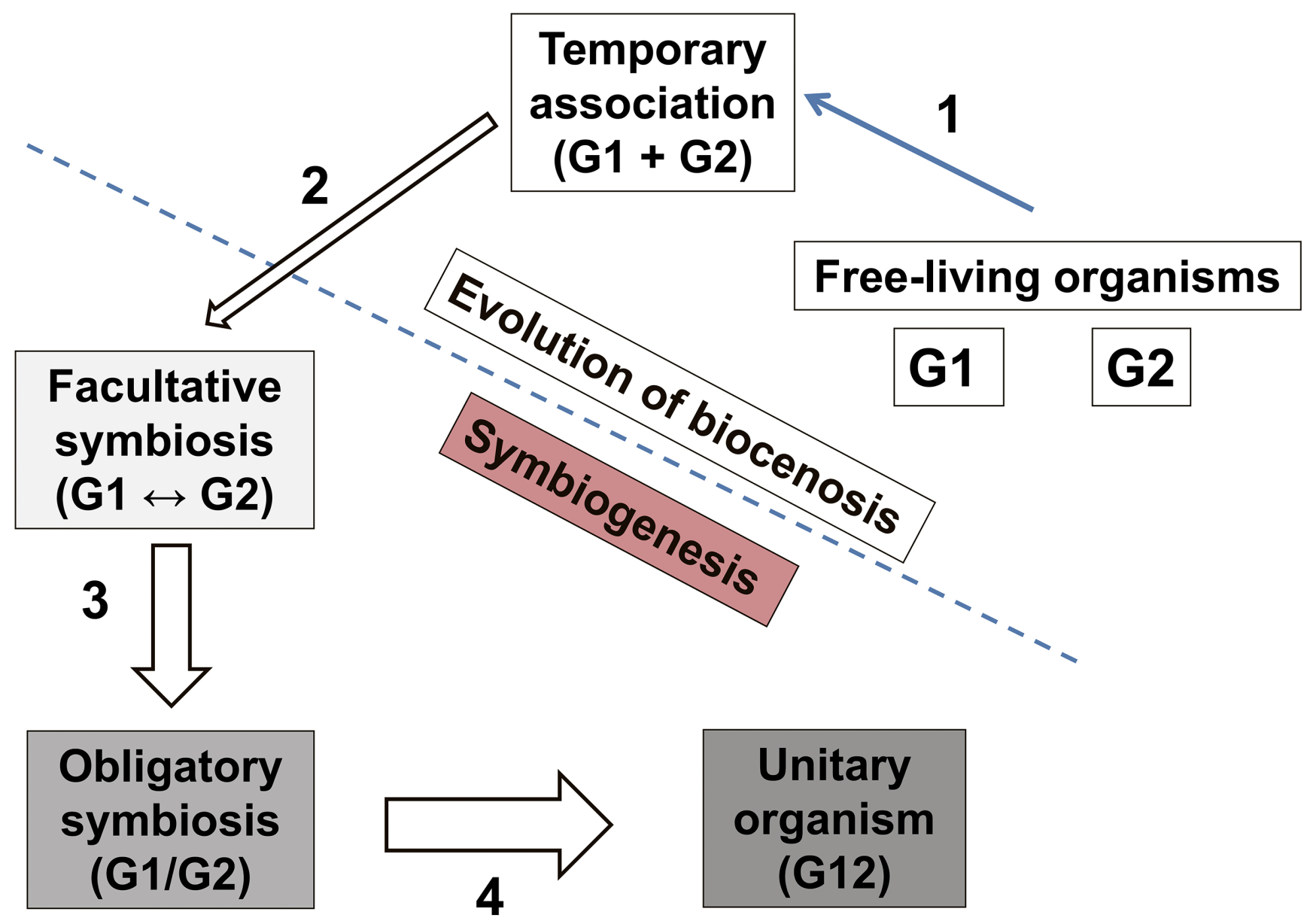

Fig. 1. The major stages of symbiogenesis. At successive evolutionary stages, the integrity of superorganismal systems is increased via the emergence of:

1) temporary associations in which the partners' genomes $(G 1+G 2)$ operate independently;

2) facultative symbioses in which partners cooperate tightly due to signal and metabolic exchange resulting in functionally integral symbiogenomes (G1 $\Theta \mathrm{G} 2)$;

3) obligatory symbioses, in which micro-partners are vertically transmitted in host generations resulting in hologenomes (G1/G2);

4) unitary organisms in which microsymbionts are transformed into organelles donating to hosts the extended genome parts, resulting in structurally integral, mosaic host genomes (G12).

jor drivers of evolutionary progress are represented by cooperative adaptations, which in some systems include "altruistic" traits that are deleterious for their owners, but are useful for their symbiotic partners (Provorov, Tikhonovich and Vorobyov, 2018).

In reciprocally beneficial (mutualistic) symbiosis, individual selection - which results from competition and antagonism ("struggle for existence") among freeliving organisms - cannot be considered the sole evolutionary factor. Nevertheless, partners' competition and antagonism are involved in the mutualism operation: in the $\mathrm{N}_{2}$-fixing Rhizobia-Legume Symbiosis (RLS), they are responsible for optimizing the partners' interactions, which involve the mutual control of cell propagation. A clear example of this control is represented by differentiation of nodule bacteria (rhizobia) into bacteroids which fix $\mathrm{N}_{2}$ actively, being devoid of reproduction due to the impacts of host-made NCR (Nodule-specific CysteineRich) peptides which are similar to defensins protecting the plants from pathogens (Berrabah, Ratet and Gourion, 2015).

According to some authors, the evolution of symbiosis is associated with the integration of partners' genomes into communalized systems called hologenomes (Zilber-Rosenberg and Rosenberg, 2008) or symbiogenomes (Tikhonovich and Provorov, 2012). Their emergence is associated with the loss by microsymbionts of Genetic INdividuality (GIN) - the ability to maintain and express their genomes, required for autonomous existence. In this paper, we address the trade-off between the loss of GIN by microsymbionts and expression of their altruism towards the hosts: this interaction allows partners to avoid the "struggle for existence" due to integration of genomes into functionally coherent units. The relationship between the loss of GIN and acquisition of altruism is considered at the successive stages of symbiosis evolution, which leads to an increased dependence of microsymbionts on hosts (Fig. 1). This dependency 
culminates in the transition of partners from functional to structural genomic integration, providing the transformation of symbiotic bacteria into the hosts' cellular organelles.

\section{Genetic individuality in symbiotic microbes}

The creation by A.S. Famintsyn (1907) and K.S.Merezhkovsky (1910) of the Symbiogenesis theory, which describes the symbiotic origin of the eukaryotic cell, resulted in a renovated vision on the driving forces of evolutionary processes. This theory, supported by genomic analysis of plastids and mitochondria (Margulis, 1996; Smith and Keeling, 2015), as well as of less specialized endosymbiotic bacteria, led to the concept of the hologenome - a superspecific system that combines the genomes of the eukaryotic host and of an associated microbial community (Zilber-Rosenberg and Rosenberg, 2008). We suggest that the initial stages of hologenome evolution are related to the partners' functional integration in facultative symbioses, which is controlled by the directly interacting genes encoding for their signal/metabolic exchange and comprising a symbiogenome (Tikhonovich and Provorov, 2012). At the next stages of coevolution, deeper integration of partners is reached in obligatory symbioses via vertical transmission by hosts of the genetically reduced symbionts, which are incapable of self-reproduction. Due to this transmission, a superspecific hologenome acquires the properties of an inheritance system, providing the prospects for transformation of endosymbionts into cellular organelles.

Therefore, symbiogenesis can be addressed as integrative evolution, based on merging the partners' genomes into communalized systems of heredity. Due to this integration, symbioses acquire their own ontogenies and phylogenies, based on developing the "emergent" properties lacking in free-living organisms. The major difference of symbiogenesis from the evolution of free-living organisms is represented by the loss of GIN, which is dependent on micropartners' systems for template processes providing the storage, transmission and expression of genetic information.

The initial stages of symbiogenesis can be addressed using the model of RLS, which demonstrates pronounced progressive evolution. From the plant side, it is manifested as the formation of specialized cellular and tissue structures in the nodules containing bacteria which form the joint $\mathrm{C} / \mathrm{N}$ metabolic pathways with hosts (Provorov, Tikhonovich and Vorobyov, 2016). Progressive rhizobia evolution involves the emergence of deeply specialized cellular forms, terminally differentiated bacteroids, and a complicated architecture of genomes their increased size and differentiation into several replicons such as circular or linear chromosomes, megaplasmids and chromids (Provorov and Tikhonovich, 2016).
It is important to note that at the initial stages of symbiogenesis, a partial loss of GIN by rhizobia occurs, associated with replacement of autonomously expressed cellular functions by complementary symbiotic functions. For example, in the evolution of slow-growing "primary" rhizobia (Bradyrhizobium), the loss of phototrophy by ancestral bacteria close to Rhodopseudomonas was accompanied by the acquisition of Nod factor synthesis. These lipo-chito-oligosaccharide signaling factors activate the development of nodules wherein bacteria are multiplied using the plant photosynthesis products (Wang, Yang, Tang and Zhu, 2012). Further RLS evolution resulted in fast-growing "secondary" rhizobia (e.g., Rhizobium and Sinorhizobium spp.), which emerged due to a broad distribution of symbiotically specialized (sym) genes in the plant-associated bacterial communities. In these rhizobia, increased $\mathrm{N}_{2}$-fixing activity is due to the elimination of negative symbiotic regulators, including the genes responsible for accumulation of storage compounds minimizing the energy costs of cellular metabolism, and for synthesis of exopolysaccharides eliciting the plant defense reactions (Provorov, et al. 2014).

\section{Natural selection and interspecies altruism}

Despite detailed genetic and molecular research on many prokaryote-eukaryote symbioses, population and ecological factors of their evolution remain poorly understood. An important role implemented in this evolution by natural selection was emphasized by A. de Bary (1879), B.M. Kozo-Polyanskiy (1923) and L. Margulis (1993), but they did not address the modes of its operation in superspecific systems. Up until now, it remains unclear whether the selection acts at the level of holobionts or if it is restricted to the partners' populations (Theis et al., 2016).

Currently, symbiosis-specific natural selection pressures are studied actively in different host-associated microorganisms (Provorov, Andronov and Onishchuk, 2017). In the RLS system, they involve: a) disruptive selection associated with adaptation of rhizobia to plant species which differ in their symbiotic affinities (results in the formation of subspecies bacterial taxons - biotypes and symbiotypes); b) frequency-dependent selection implemented when rhizobia migrate from soil and the rhizosphere to the nodular niches (results in increased population diversity); c) group (inter-deme, kin) selection, which is induced by hosts in the clonal populations of endosymbionts resulting in their improved $\mathrm{N}_{2}$-fixing activity.

The reduction of microsymbionts' GIN is an evolutionary strategy which cannot be supported by the theory of natural selection, but can be described using "non-Darwinian" models based on biological altruism. This altru- 
ism was initially defined as an intraspecific interaction, in which the fitness of some individuals is increased due to its decrease in others. The models of altruism evolution were forwarded by J.B.S. Haldane (1932) and his followers (Hamilton, 1964; Maynard Smith, 1964) using the examples of offspring care and other forms of social behavior. The "Hamilton inequality" proposed by these authors $(k \bullet b>c)$ sets the conditions for a balance between the adaptive benefit (b) obtained by recipients of altruism and the cost (c) experienced by donors of altruism as dependent on the kin relatedness of donors and recipients $(0<k \leq 1)$. This approach allows us to consider altruism as a group adaptation based on decreased fitness of some individuals supported by kin selection in favor of their close relatives (Maynard Smith, 1964). The effectiveness of these adaptations depends on the genetic coherence of the group: it is maximal in clonal organisms $(k=1)$, intermediate in cross-breeding organisms $(0<k \leq 0.5)$ and is not possible for interspecies interactions $(k=0)$.

For a long time, interspecific altruism was considered either impossible (Darwin, 1872) or limited to the traits emerging randomly in symbiotic organisms as by-products of their individual adaptations (Maynard Smith, 1989). An important step in overcoming these limitations was taken by S. Frank (1994), who modified the models of intraspecific altruism for analyzing symbiotic relationships. He used the systems of several "Hamilton inequalities" wherein the kinship measure $(k)$ was replaced by the coefficient of correlation $(r)$ between the fitness gains obtained by partners of mutualistic symbiosis. In a simplest system of two interacting species, partners' altruism is implemented if the inequalities are valid: $r \bullet b_{1}>c_{1} ; r \bullet b_{2}>c_{2}$, reflecting the mutualistic interactions $(r>0)$, where $b_{1} / c_{1}$ and $b_{2} / c_{2}$ represent the benefit/cost ratios of symbiotic interactions determined for each partner. Expanding the limits of $r$ variation opens the possibility of describing different types of symbiosis: antagonism $(r<0)$ and commensalism $(r=0)$.

This approach suggests that in the RLS system, altruism of microsymbionts towards their hosts may be controlled by kin selection, which operates in the plant-associated bacterial populations. Herein, the host represents a mediator in the transfer of altruism impacts from its donors (intracellular bacteroids which fix $\mathrm{N}_{2}$ actively, but are not capable of reproduction) to recipients (extracellular non- $\mathrm{N}_{2}$-fixing bacteria that retain reproductive activity), while this mediating is compensated for host plants via fixed nitrogen provided by rhizobia (Provorov and Vorobyov, 2015). Another example of this host-directed altruism is represented by symbiotic cyanobacteria: up to $80 \%$ of Nostoc punctiforme cells may be reorganized into non-reproducible $\mathrm{N}_{2}$-fixing heterocysts when forming intracellular symbiosis with Gunnera plants, while in free-living cyanobacteria heterocysts are formed by $10 \%$ of cells (Meeks and Elhai, 2002). Mathematically, altruis- tic interactions can be represented as "inclusive fitness" (Hamilton, 1964), which addresses the allocation of adaptive impacts among the symbiotic partners.

Importantly, the suggested approach differs significantly from the representation of mutualistic interactions as partners' "reciprocal exploitation", e.g., the equivalent exchange of bacteria and plants by $\mathrm{N}$ and $\mathrm{C}$ nutrients in $\mathrm{N}_{2}$-fixing symbioses. Clearly, this exploitation represents the simplest form of cooperation revealed in symbiotic partners, which is sometimes considered "refined parasitism" (Djordjevic, Gabriel and Rolfe, 1987; Lodeiro et al., 2004) or "sympathogenesis" (Spaink, 1995). In the RLS system, metabolic exchange is combined with intensive competition between microbial and plant cells for the photosynthesis products, as well as with the operation of defensive factors (reactive oxygen species, NCR peptides) that limit bacterial proliferation in the nodules. However, the emerging "conflict of interests" is transient: partners' competition and antagonism contribute to the persistence of the holobiont, providing its ecological sustainability.

In an evolutionary perspective, this partners' conflict is resolved when the functional genetic integration is accompanied by their structural integration associated with the "endosymbiotic" transfer of microbial genes into the host chromosomes (Smith and Keeling, 2015). Due to this transfer, microsymbionts lose their GIN, while their genes are transformed into the regular components of host genomes. The resulted cooperation may be interpreted in terms of genomic complementation (Tikhonovich et al., 2015), but is not restricted to it: functional interaction of partners' genomes in facultative symbioses provides the background for their structural integration in obligatory symbioses. So-called "forced" altruism (Darlington, 1978) may be involved in the later symbiosis type since the expression of beneficial traits becomes mandatory for the survival of microbes in the host-provided symbiotic niches. Therefore, the late stages of symbiogenesis involve the loss of GIN by the obligatory symbionts, ensuring the conditions for their transition into organelles.

\section{Conclusion}

Our paper argues that symbiogenesis is an evolutionary strategy for partners' genomic integration, resulting from interspecies altruism which is based on the microsymbionts' "refusal" of individual adaptations in favor of the increased fitness of hosts. In facultative symbioses, the hosts (recipients of altruism) compensate for their microbial partners' (donors of altruism) decrease in fitness; however, this compensation is obtained not by those cellular individuals which express the altruistic traits, but by their kin relatives. In facultatively developed RLS, the altruism recipients are represented by non-differentiated bacteria, which occupy the subcellular niches (e.g., infec- 

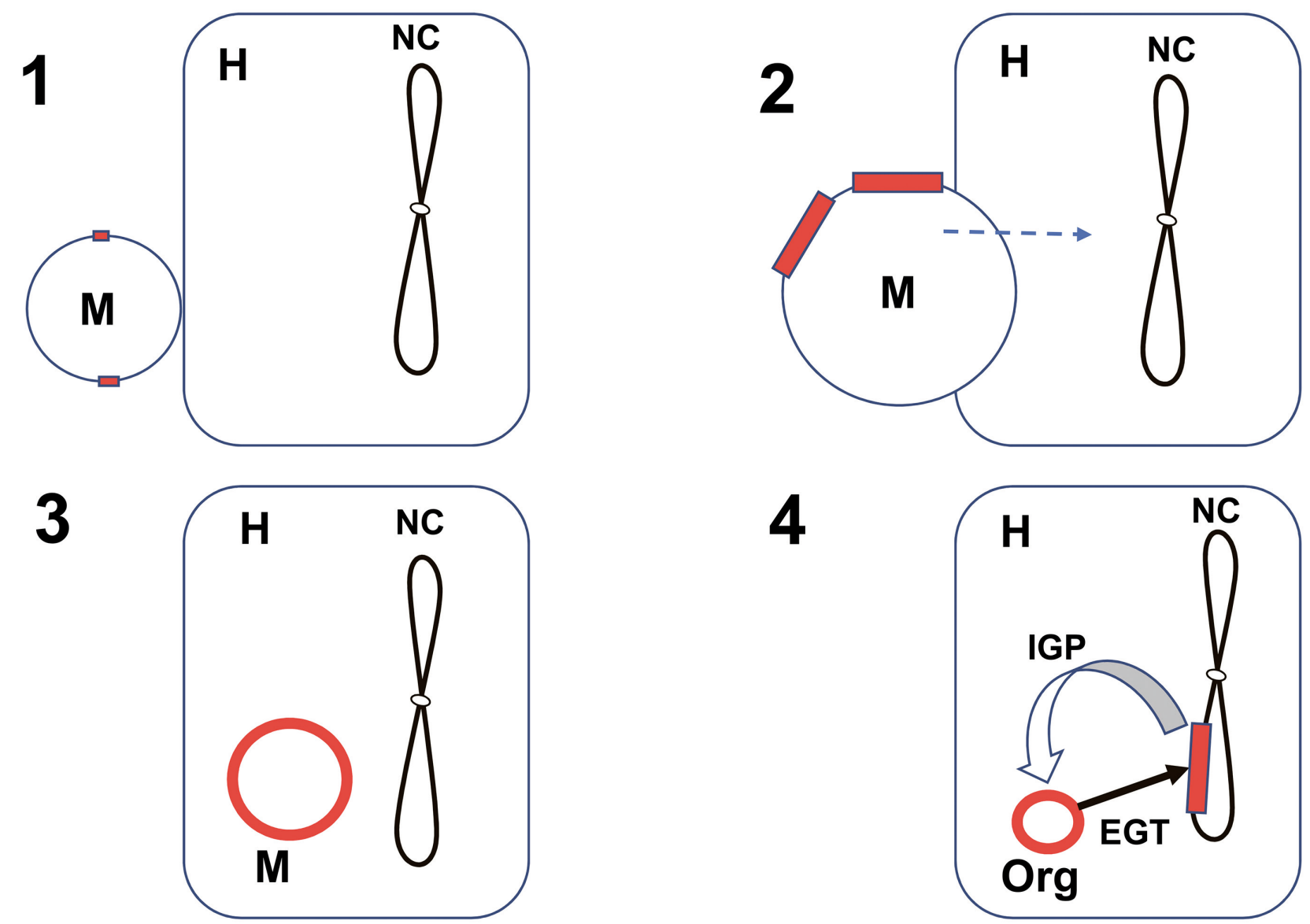

Fig. 2. Architectures of superspecific genetic systems as determined by the dependence of Microsymbionts (M) on Hosts $(H)$.

1) Conditional dependence. Genes that are specifically involved in symbiosis with $\mathrm{H}$ represent a minor part of $\mathrm{M}$ genome.

2) Facultative dependence. Symbiotically specialized genes comprise the extended clusters in M genome; at certain stages of interaction, M colonize the endosymbiotic, sometimes intracellular niches (dashed arrow).

3) Obligatory dependence. The reduced $\mathrm{M}$ genome is involved in symbiosis entirely, since $\mathrm{M}$ are persisting constantly (usually intracellularly) inside $\mathrm{H}$.

4) Absolute dependence. $M$ are transformed into cellular Organelles (Org) with the rudimentary genomes transmitting genes to Nuclear Chromosomes (NC) via Endosymbiotic Gene Transfer (EGT). For maintenance of Org, massive Import of Gene Products (IGP) is implemented.

Table. Evolution of host-associated bacteria at the successive stages of symbiogenesis

\begin{tabular}{|c|c|c|c|c|c|c|}
\hline \multirow[b]{2}{*}{$\begin{array}{c}\text { Dependence of } \\
\text { microsymbionts on hosts }\end{array}$} & \multicolumn{6}{|c|}{ Properties of microsymbionts } \\
\hline & $\begin{array}{l}\text { Niches occupied } \\
\text { in hosts }\end{array}$ & $\begin{array}{l}\text { Genome } \\
\text { types }\end{array}$ & $\begin{array}{c}\text { Genetic } \\
\text { individuality }\end{array}$ & $\begin{array}{l}\text { Host-provided } \\
\text { products }\end{array}$ & $\begin{array}{l}\text { Gene } \\
\text { transfer to } \\
\text { hosts* }\end{array}$ & $\begin{array}{l}\text { Superspecific } \\
\text { genetic systems }\end{array}$ \\
\hline $\begin{array}{l}\text { Conditional (genetic special- } \\
\text { ization of bacteria for sym- } \\
\text { biosis is poor) }\end{array}$ & \begin{tabular}{|l|} 
Spontaneously colo- \\
nized surfaces or \\
extracellular spaces
\end{tabular} & $\begin{array}{l}\text { Unitary or } \\
\text { multipartite }\end{array}$ & Retained & $\begin{array}{l}\text { Spontaneously ex- } \\
\text { creted metabolites } \\
\text { (e.g., root exudates) }\end{array}$ & Absent & Not available \\
\hline $\begin{array}{l}\text { Facultative (bacteria combine } \\
\text { the abilities for genetically } \\
\text { specialized symbioses and of } \\
\text { autonomous existence) }\end{array}$ & $\begin{array}{l}\text { Regularly colo- } \\
\text { nized inter-and } \\
\text { intracellular } \\
\text { niches }\end{array}$ & $\begin{array}{l}\text { Unitary, tend- } \\
\text { ing to be reor- } \\
\text { ganized into } \\
\text { multipartite }\end{array}$ & $\begin{array}{l}\text { May be restricted } \\
\text { (loss of free-living } \\
\text { functions interfer- } \\
\text { ing with symbiosis) }\end{array}$ & $\begin{array}{l}\text { C- and N-nutrients } \\
\text { transferred via } \\
\text { inter-organism bio- } \\
\text { chemical pathways }\end{array}$ & $\begin{array}{l}\text { Occurs } \\
\text { in some } \\
\text { systems } \\
(\mathrm{HGT})^{\star \star}\end{array}$ & $\begin{array}{l}\text { Functionally inte- } \\
\text { gral, horizontally } \\
\text { transmitted (sym- } \\
\text { biogenomes) }\end{array}$ \\
\hline $\begin{array}{l}\text { Obligatory (bacteria can not } \\
\text { reproduce outside the hosts) }\end{array}$ & $\begin{array}{l}\text { Specialized cells } \\
\text { or sub-cellular } \\
\text { compartments }\end{array}$ & Reduced & $\begin{array}{l}\text { Markedly reduced } \\
\text { (many housekeeping } \\
\text { functions are lost) }\end{array}$ & $\begin{array}{l}\text { Essential metabo- } \\
\text { lites (amino acids, } \\
\text { cofactors, ATP) }\end{array}$ & $\begin{array}{l}\text { Sporadic } \\
(\mathrm{HGT})^{\star \star \star}\end{array}$ & $\begin{array}{l}\text { Functionally integral, } \\
\text { vertically transmit- } \\
\text { ted (hologenomes) }\end{array}$ \\
\hline $\begin{array}{l}\text { Absolute (organelles are not } \\
\text { capable of maintenance and } \\
\text { expression of the genomes) }\end{array}$ & All cells & $\begin{array}{l}\text { Rudimentary } \\
\text { or absent }\end{array}$ & $\begin{array}{l}\text { Completely lost (can } \\
\text { not implement the } \\
\text { template processes) }\end{array}$ & $\begin{array}{l}\text { Informational mac- } \\
\text { romolecules (RNAs, } \\
\text { proteins) }\end{array}$ & $\begin{array}{l}\text { Regular } \\
\text { (EGT) }\end{array}$ & $\begin{array}{l}\text { Structurally inte- } \\
\text { gral (mosaic ge- } \\
\text { nomes of hosts) }\end{array}$ \\
\hline
\end{tabular}

* Modes of gene transfer: HGT — horizontal, EGT — endosymbiotic.

** Genetic parasitism of Agrobacterium on plants based on transfer of specialized microbial genes (T-DNA) into the host chromosomes.

*** Different segments of Wolbachia genomes or the full-size genomes may be integrated into the host chromosomes. 
tion threads) in nodules, maintaining viability upon the completion of symbiosis. The altruism donors are represented by non-reproducing intracellular bacteroids which die after nodule senescence. This interaction creates the conditions for kin selection, which at the next stages of evolution results in a "forced altruism" in obligatory symbioses and culminates in the loss of GIN upon transformation of microorganisms into cellular organelles.

Therefore, the development of interspecies altruism and the loss of GIN are tightly linked processes since they are based on the loss of microsymbionts' individual adaptations resulting in the partners' genetic integration. At the genomic level, these processes can be represented by the evolutionary pathway starting from the functionally integral symbiogenomes which are transferred into the structurally integral, vertically transmitted hologenomes, and then into the host genomes which are mosaic in origin, but are unitary in their functional organization (Fig. 2, Table). In the altruistically organized symbiotic system, microbial partners "delegate" to hosts their control over vital functions, in some cases, together with the relevant genes encoding for these functions. Importantly, in facultative symbionts, the loss of individual adaptations occurs at the epigenetic level (irreversible repression of many genes in rhizobia bacteroids which retain full-sized genomes), while in obligatory symbionts this loss occurs at the genomic level (e.g., elimination of significant genome parts in insect endocytobionts) and culminates in a complete loss of genomes in some organelles (mitosomes, hydrogenosomes).

It is important to note that the loss of GIN, represented by mathematical models as a redistribution of adaptive impacts between partners ("inclusive fitness"), at the molecular level is manifested as a transfer of microbial genes to the host, which then acquires an "inclusive" genome. Therefore, phenotypes of microsymbionts (organelles) are determined not only by their intrinsic genomes, but also by genes that have been previously donated to the hosts.

Importantly, genome-free organelles arising at the final stages of symbiogenesis retain the basic properties of living creatures - metabolism and reproduction, representing the organisms lacking their own genomes. This is why the loss of GIN can be assumed as a reversal of symbiotic bacteria to ancestral cellular forms, which, according to some authors (Oparin, 1957; Provorov, Tikhonovich and Vorobyov, 2018) were represented by proto-cells implementing specific metabolic functions but lacking the genomes encoding for these functions.

\section{References}

Berrabah, F., Ratet, P., and Gourion, B. 2015. Multiple steps control immunity during the intracellular accommodation of rhizobia. Journal of Experimental Botany 66(7):1977-1985. https://doi.org/10.1093/jxb/eru545
Darlington, P.J. 1978. Altruism: its characteristics and evolution. Proceedings of the National Academy of Sciences USA 75(1):385-389. https://doi.org/10.1073/pnas.75.1.385

Darwin, C. 1872 . The origin of species by means of natural selection (6th edn). London: John Murray.

de Bary, A. 1879. Die erscheinung der symbiose. Strassburg:Verlag Von K.J. Trübner. https://doi.org/10.1515/9783111471839

Famintsyn, A.S. 1907. The role of symbiosis in the evolution of organisms. Zapiski Imperatorskoy Academii Nauk. Ser. 8. 20:1-14. (In Russian)

Frank, S. A. 1994. Genetics of mutualism: the evolution of altruism between species. Journal of Theoretical Biology 170(2):393-400. https://doi.org/10.1006/jtbi.1994.1200

Haldane, J. B. S. 1932. The causes of evolution. NY: Longmans, Green \& Co.

Hamilton, W. D.J. 1964. The genetical evolution of social behavior. Journal of Theoretical Biology 7(1):1-16. https:// doi.org/10.1016/0022-5193(64)90038-4

Djordjevic, M. A., Gabriel, D. W., and Rolfe, B. G. 1987. Rhizobium - the refined parasite of legumes. Annual Review of Phytopathology 25:145-168. https://doi.org/10.1146/ annurev.py.25.090187.001045

Kozo-Polyansky, B. M. 1924. New principle of biology. Overview of the symbiogenesis theory. Moscow, Russia: Puchina. (In Russian)

Lodeiro, A. R., Lopez-Garcia, S. L., Althabegoiti, M. J., Mongiardini, E. J., Perez-Jimenez, J., and Quelas J. I. 2004. Parasitic traits and plant defenses in the rhizobia-legume symbiosis. Recent research developments in plant pathology 3(1):125-166.

Margulis, L. 1993. Symbiosis in cell evolution (2nd edn). NY: Freeman.

Margulis, L. 1996. Archaeal-eubacterial mergers in the origin of Eukarya: phylogenetic classification of life. Proceedings of the National Academy of Sciences USA 93(3):1071-1076. https://doi.org/10.1073/pnas.93.3.1071

Maynard Smith, J. 1964. Group selection and kin selection. Nature 201(4924):1145-1147. https://doi. org/10.1038/2011145a0

Maynard Smith, J. 1989. Generating novelty by symbiosis. Nature 341(6240):284-285. https://doi.org/10.1038/341284a0

Meeks, J. C. and Elhai, J. 2002. Regulation of cellular differentiation in filamentous cyanobacteria in free-living and plant-associated symbiotic growth states. Microbiology and Molecular Biology Reviews 66(1):94-121. https://doi. org/10.1128/mmbr.66.1.94-121.2002

Mereschkowsky, C. 1910. Theorie der zwei Plasmaarten als Grundlage der Symbiogenesis, einer neuen Lehre von der Entstehung der Organismen. Biologisches Centralblatt 30:278-288.

Oparin, A. I. 1957. The origin of life on the earth (3rd edn). NY: Academic Press.

Provorov, N.A., Andronov, E.E., and Onishchuk, O.P. 2017. Forms of natural selection controlling the genomic evolution in nodule bacteria. Russian Journal of Genetics 53(4):411-419. https://doi.org/10.1134/ S1022795417040123

Provorov, N. A. and Tikhonovich, I. A. 2016. Genetic bases of evolution in bacterial symbionts of plants. St.-Petersburg, Russia: Inform-Navigator. (In Russian)

Provorov, N.A. and Vorobyov, N. I. 2015. Evolution of hostbeneficial traits in nitrogen-fixing bacteria: modeling and construction of systems for interspecies altruism. Applied Biochemistry and Microbiology 51(4):363-370. https://doi.org/10.1134/S0003683815040146

Provorov, N. A., Onishchuk, O. P., Yurgel, S. N., Kurchak, O. N., Chizhevaskaya, E.P., Vorobyov, N.I., Zatovskaya, T. V., and Simarov, B. V. 2014. Construction of highly-effective 
symbiotic bacteria: evolutionary models and genetic approaches. Russian Journal of Genetics 50(11):1273-1285. https://doi.org/10.1134/S1022795414110118

Provorov, N.A., Tikhonovich, I. A., and Vorobyov, N.I. 2016. Symbiogenesis as a model for reconstructing the early stages of genome evolution. Russian Journal of Genetics 52(2):117-124. https://doi.org/10.1134/ S1022795416020101

Provorov, N. A., Tikhonovich, I. A., and Vorobyov, N. I. 2018. Symbiosis and symbiogenesis. St.-Petersburg, Russia: Inform-Navigator. (In Russian)

Smith, D. R. and Keeling, P.J. 2015. Mitochondrial and plastid genome architecture: reoccurring themes, but significant differences at the extremes. Proceedings of the National Academy of Sciences USA 112(33):10177-10184. https://doi.org/10.1073/pnas.1422049112

Spaink, H. P. 1995. The molecular basis of infection and nodulation by rhizobia: the ins and outs of sympathogenesis. Annual Review of Phytopathology 33:345-368. https://doi. org/10.1146/annurev.py.33.090195.002021

Theis, K. R., Dheilly, N. M., Klassen, J. L., Brucker, R. M., Baines, J. F., Bosch, T. C. G., Cryan, J. F., Gilbert, S. F., Goodnight, C. J., Lloyd, E. A., Sapp, J., Vandenkoornhuyse, P., Zilber-Rosenberg, I., Rosenberg, E., and Bordenstein, S. R.
2016. Getting the hologenome concept right: a co-evolutionary framework for hosts and their microbiomes. mSystems 1(2):e00028-16. https://doi.org/10.1128/mSystems.00028-16

Tikhonovich, I.A. and Provorov, N.A. 2012. Development of symbiogenetic approaches for studying variation and heredity of superspecies systems. Russian Journal of Genetics 48(4):357-368. https://doi.org/10.1134/ S1022795412040126

Tikhonovich, I. A., Andronov, E. E., Borisov, A. Yu., Dolgikh, E. A., Zhernakov, A. I., Provorov, N. A., Rumyantseva, M. L., and Simarov, B. V. 2015. The principle of genome complementarity in the enhancement of plant adaptive capacities. Russian Journal of Genetics 51(9):831-846. https:// doi.org/10.1134/S1022795415090124

Wang, D., Yang, S., Tang, F., and Zhu, H. 2012. Symbiosis specificity in the legume - rhizobial mutualism. Cellular Microbiology 14(3):334-342. https://doi.org/10.1111/ j.1462-5822.2011.01736.x

Zilber-Rosenberg, I. and Rosenberg, E. 2008. Role of microorganisms in the evolution of animals and plants: the hologenome theory of evolution. FEMS Microbiology Reviews 32(3):723-735. https://doi.org/10.1111/j.15746976.2008.00123.x 